\title{
Jean-Paul Marat. Médico, científico y revolucionario
}

\author{
JAIME CERDA L.
}

Departamento de Salud Pública, Facultad de Medicina, Pontificia Universidad Católica de Chile. Santiago de Chile. Recibido el 27 de noviembre de 2008, aceptado el 3 de noviembre de 2009 Correspondencia a: Dr. Jaime Cerda L. Departamento de Salud Pública, Facultad de Medicina Pontificia Universidad Católica de Chile.

Marcoleta 434, Santiago-Chile. Tel.: (56-2) 3543802 Fax: (56-2) 6331840 E-mail: jcerda@med.puc.cl

\section{Jean-Paul Marat. Physician, scientist and revolutionary}

\begin{abstract}
Physician, scientist and revolutionary are the biographical aspects that better summarize the life of Jean-Paul Marat (1743-1793). Due to the role that he played during the French Revolution, his work as a physician and scientist, prior to the events of 1789, was forgotten. Marat made important contributions in the area of optics and electricity, reflected in numerous publications, as well as translating Newton's Opticks (1787). Well known for his radical and aggressive ideas, his political vocation led him to embrace the revolutionary cause after the events of the Bastille. His figure was not indifferent for his contemporaries; although considered a hero by the poorest citizens, aristocrats and bourgeois considered him a cruel extremist. During the last years of his life he suffered a cutaneous disease, the diagnosis of which is still a matter of controversy. Proposed diagnoses include eczema, seborrhoeic dermatitis, scabies and dermatitis herpetiformis, among others. Marat was assassinated by Charlotte Corday in 1793, becoming a martyr for some segments of the society, that worshiped his memory. He was a man with a complex and curious personality whose figure and legacy are still a matter of discussion.
\end{abstract}

(Rev Med Chile 2010; 138: 124-127).

Key words: Biography; French revolution; Optics and photonics.
$\mathrm{P}$ ocos personajes históricos generan opiniones tan contrapuestas como Jean-Paul Marat (1743-1793) (Figura 1). Para los desposeídos, Marat fue un héroe y mártir de la Revolución Francesa; por el contrario, aristócratas y burgueses lo consideraban un extremista sanguinario. Su participación durante y con posterioridad a los acontecimientos de 1789 ha sido descrita en detalle por numerosos historiadores, al igual que su trágica muerte, inmortalizada en 1793 por el pintor Jacques-Louis David (Figura 2). Sin embargo, poco se ha escrito en torno a otros aspectos de su vida, en especial sobre su quehacer como médico y científico, desarrollado con tenacidad antes del inicio de la Revolución. El presente artículo trae al presente aspectos biográficos de este singular personaje, analizando las diversas facetas que desarrolló durante su vida, además de hacer referencia a aspectos clínicos acerca de la invalidante enfermedad cutánea que le acompañó hasta el momento de su muerte, motivo de controversia diagnóstica hasta el día de hoy.

\section{Marat, el médico}

Hijo mayor de padre de origen sardo convertido al calvinismo (Giovanni Mara) y de madre ginebrina (Louise Cabrol), Jean-Paul Marat nació el 24 de mayo de 1743 en la localidad de Boudry, cantón de Neuchâtel, Suiza. Tras la muerte de su madre, a sus cortos dieciséis años abandonó el hogar familiar, 


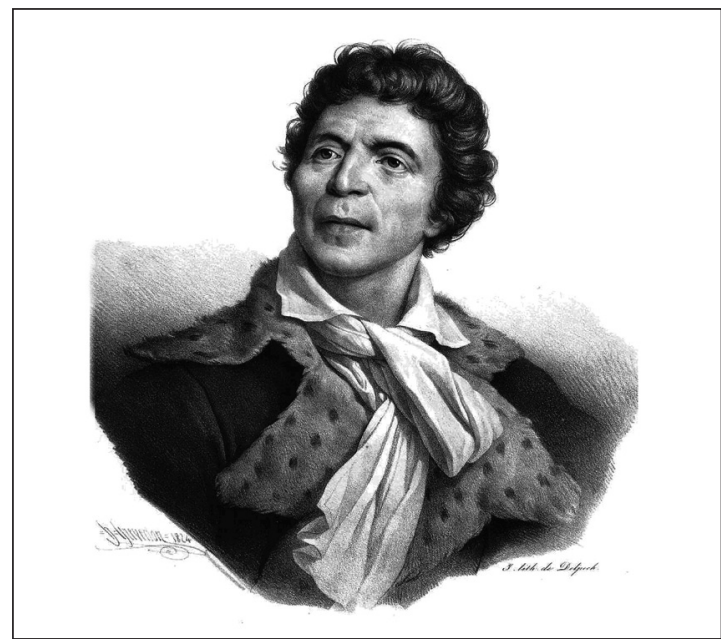

Figura 1. Jean-Paul Marat, según grabado de 1824 (Reproducción fotográfica de dominio público).

iniciando un peregrinaje que lo llevaría a Burdeos y París, lugares donde estudió medicina. En 1767 llegó a Inglaterra, país en el cual residió durante una década, completó sus estudios médicos y practicó la profesión, recibiendo en 1775 el grado honorífico de doctor en medicina por la Universidad de San Andrés (Edimburgo) tras escribir un ensayo sobre la gonorrea. Luego de publicar en Londres un estudio titulado "Investigación sobre la naturaleza, causa y cura de una enfermedad ocular singular", en 1777 regresó a Francia, específicamente a París. En esta ciudad, su excelente reputación como médico - unido al apoyo de la marquesa de l'Aubespine, a quien trató exitosamente una afección pulmonar y de quien posteriomente se transformó en amante- le permitió acceder al cargo de médico del cuerpo de guardia del conde d'Artois, hermano menor de Luis XVI y futuro Carlos X, rey de Francia durante la Restauración, a pesar de su declarada postura antimonárquica ${ }^{1-3}$.

La remuneración de 2.000 libras anuales, unida a los ingresos recibidos a través de su práctica privada brindó a Marat una holgada situación económica, permitiéndole montar un laboratorio. Prontamente publicó estudios sobre óptica y electricidad, sus disciplinas científicas favoritas, entre los cuales destacan "Investigaciones físicas sobre la electricidad" (1782), "Investigaciones sobre electricidad médica" y "Nociones elementales de óptica” (1784). Sus experimentos en estas áreas atrajeron admiradores y pupilos e interesaron a personalidades de renombre

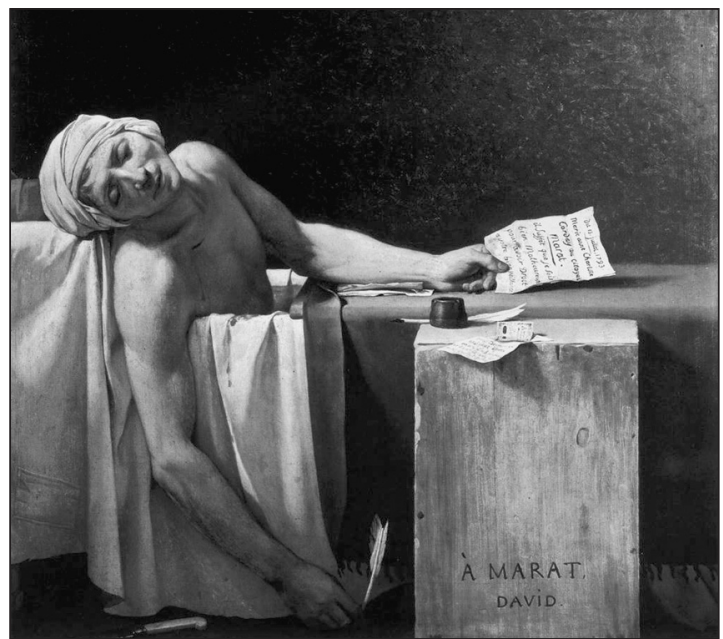

Figura 2. "La muerte de Marat" (Jacques-Louis David, 1793). Colección Museos Reales de Bellas Artes de Bélgica (Reproducción fotográfica de dominio público).

tales como Benjamín Franklin, quien solía visitarle. Muy a su pesar, sus investigaciones no fueron bien recibidas por la Académie des Sciences, la cual rechazó su tan añorada membresía, principalmente debido a su osadía de disentir con Isaac Newton (16461727) en torno a ciertas concepciones científicas. La obtención del premio de la Academia de Rouen por su tesis sobre la electricidad médica (1783) tampoco fue un argumento suficiente para ingresar a la Académie, hecho calificado por el mismo Goethe-cuyo inconmensurable legado intelectual incluye estudios sobre óptica- como un claro ejemplo de despotismo científico. El rechazo de sus pares gatilló en Marat una idea obsesiva de persecución en su contra. Tras la renuncia en 1786 a su trabajo en la corte, Marat tradujo la Opticks de Newton (1787) y redactó sus "Memorias académicas, o nuevos descubrimientos acerca de la luz" (1788). Para aquel entonces, la Revolución Francesa había completado su proceso de gestación, causa a la cual Marat se abocaría por completo y que le permitiría, entre otras cosas, vengarse de quienes consideraba sus perseguidores. Transcurrido menos de un lustro, durante el Reinado del Terror (1793) se suprimiría la Académie des Sciences. Marat, para aquel entonces convertido en un caudillo de la Revolución, concretó su venganza "académica" acusando a Antoine Lavoisier - miembro aristócrata de la Académie y genio brillante, considerado el padre de la química moderna- de haber participado en complots absurdos contra el pueblo de Francia. 
Un tribunal revolucionario condenó a éste último a muerte, siendo guillotinado en $1794^{4}$.

\section{Marat, el revolucionario}

Para 1789, Marat se había abocado por completo a la política, principalmente a través de la escritura de una serie de obras tales como "Ofrenda a la Patria", "La Constitución" y "Cuadro de los vicios de la Constitución Inglesa”. Su acercamiento a la política se había iniciado casi dos décadas antes, pues en 1772 había publicado su "Ensayo filosófico sobre el hombre" y en 1774 su libro "Las cadenas de la esclavitud", en el cual criticaba la corrupción del sistema político inglés y la miseria de las ciudades. En esta obra, Marat reivindica el derecho del pueblo a su libertad, la cual consideraba que conseguiría solamente por medio de una insurrección violenta ${ }^{1-3}$.

En septiembre de 1789, ocurridos los hechos de la Bastilla, Marat financió e inició la redacción de su propio periódico de opinión, llamado L'Ami du Peuple ("El Amigo del Pueblo"). Con un tiraje de 2.000 ejemplares, L'Ami du Peuple tuvo una gran influencia en la Revolución. Redactado en un tono agresivo, sus páginas fueron una tribuna perfecta para Marat, a través de las cuales atacó descarnadamente a todos quienes consideraba "enemigos de la Revolución", sean partidarios del antiguo régimen o bien revolucionarios moderados, llamando a la violencia, hecho que motivó varias suspensiones del periódico. Su actuar no dejó indiferente a nadie, ganándose por un lado la admiración y adoración de los sectores más marginales y por otro peligrosas enemistades. Temerosos de su fanatismo extremo (Marat afirmaba: "yo soy la rabia, la rabia justa del pueblo, por eso me escuchan y creen en mí”), sus enemigos le persiguieron, forzándole a huir a Inglaterra por tres meses. En 1790, de vuelta en París, retomó la publicación del periódico, mas por temor a represalias debió esconderse en las insalubres catacumbas parisinas, una red de túneles y cuartos subterráneos convertidos en cementerio común a fines del siglo XVIII. Tras ser declarada la República Francesa (1792), Marat dejó de publicar L’Ami du Peuple, dando paso al Journal de la République Française ("Diario de la República Francesa") nombrado en honor a la naciente república, tribuna en la cual mantuvo su estilo crítico y violento. Muerto el rey Luis XVI (1793), Marat luchó tenazmente contra la facción de los girondinos, grupo al cual consideraba enemigos encubiertos de la Revolución. Ese mismo año ocurriría su trágica muerte ${ }^{1-3}$.

\section{La enfermedad de Marat}

El comienzo de su singular enfermedad se remontaría entre tres y cinco años antes de su muerte, no existiendo consenso entre los historiadores sobre su etiología. Jelinek (1979) describió la enfermedad de Marat como "una afección cutánea crónica y adquirida, afectándole en una edad media (45-50 años), la cual comenzó en la zona perineal, se expandió a la mayoría de su cuerpo, era intensamente pruriginosa, persistió durante largo tiempo y no demostró ser letal"'. La enfermedad comenzó a agravarse, tornándose intensamente pruriginosa, comprometiendo su calidad de vida y forzándole a permanecer por largas horas sumergido en una bañera, cuyas aguas medicinales le proporcionaban algún alivio. La bañera tenía forma de zapato y le permitía trabajar y dialogar con diversas personas mientras se encontraba en su interior.

A lo largo de la historia las hipótesis diagnósticas planteadas han sido variadas, reflejo de la incertidumbre en torno al diagnóstico real. Sus enemigos esparcieron el rumor de que se trataba de una erupción sifilítica. Otros diagnósticos diferenciales han sido eczema (Cabanès, 1913), dermatitis herpetiforme (Graham-Little, 1916), eczema liquenificado (Hart, 1924), escabiosis (Bayon, 1945) y dermatitis seborreica (Dale, 1952). Tanto Scarlett (1930) como Jelinek (1979) coinciden con Graham-Little en el diagnóstico de dermatitis herpetiforme $e^{6}$, siendo una hipótesis plausible con los síntomas y signos referidos por los historiadores. Al igual que la enfermedad celíaca, la dermatitis herpetiforme presenta como sustrato fisiopatológico una intolerancia intestinal al gluten de la dieta, presente en numerosos alimentos. La dermatitis herpetiforme afecta mayormente a varones, siendo su edad de inicio más frecuente entre la segunda y cuarta década de vida. Las lesiones primarias consisten en pápulas eritematosas o vesículas con tendencia a adoptar una configuración herpetiforme. Las lesiones son intensamente pruriginosas y se distribuyen en forma simétrica sobre superficies extensoras, principalmente codos, rodillas, hombros, región sacra y glúteos. Los pacientes a menudo presentan lesiones de rascado. Con respecto a su diagnóstico, un signo patognomónico lo constituye el hallazgo de depósitos granulares de IgA en la unión dermoepidérmica de la piel sana perilesional. La supresión del gluten de la dieta tiene como resultado una mejoría de las lesiones cutánea en un período de meses, así como una reducción de los episodios de recaída ${ }^{7,8}$. En 1884 (casi un siglo des- 
Jean-Paul Marat. Médico, científico y revolucionario - J. Cerda L.

pués del fallecimiento de Marat) el Dr. Louis Duhring (1845-1913) realizó la primera descripción clínica de esta patología a modo de entidad clínica; por su parte, la primera sugerencia de que los pacientes con dermatitis herpetiforme presentan una enteropatía idéntica a la enfermedad celíaca data de $1967^{9}$.

Otro aspecto que ha atraído a historiadores ha sido la posible relación de tipo causa-efecto entre la enfermedad de Marat y su temperamento violento (o viceversa), no existiendo consenso. Posiblemente tanto las circunstancias históricas como su temperamento jugaron un rol, total o parcial, en la génesis de la enfermedad y ésta, a su vez, afectó su carácter. Si bien el temperamento característico de Marat es temporalmente anterior al desarrollo de su enfermedad, lo cierto es que el agravamiento de esta última coincidió con una intensificación del primero ${ }^{6}$. Aparentemente el padecer de una patología cutánea crónica tiene consecuencias importantes sobre la personalidad. Además de Marat, otros personajes históricos de ideas revolucionarias tuvieron similares padecimientos; al respecto, Karl Marx (1818-1883) habría sufrido una invalidante hidradenitis supurati$\mathrm{va}^{10}$, mientras que Josef Stalin (1879-1953) padecía de psoriasis ${ }^{11}$. La disminución de calidad de vida asociada a estas enfermedades posiblemente tuvo un efecto psicológico no despreciable en estos tres personajes, posiblemente ejerciendo alguna influencia en lo que fueron sus ideas y comportamiento. En palabras de Shuster, quien describiera la hidradenitis supurativa de Karl Marx, "la piel es un órgano de comunicación y sus trastornos producen gran distrés psicológico; genera rechazo y disgusto, depresión de la imagen corporal, del ánimo y del bienestar"10.

\section{Su trágica muerte}

El 13 de julio de 1793, estando en su bañera, Marat recibió la visita de la joven Charlotte Corday, quien decía traer los nombres de algunos girondinos enemigos de la revolución, quienes habían huido a la ciudad de Caen. Cuenta la historia que Marat apuntó sus nombres y afirmó que debían ser guillotinados, tras lo cual Corday extrajo un puñal, hiriendo mortalmente a Marat (Figura 2). La joven era hija de girondinos convertidos en realistas. En el juicio llevado a cabo en su contra por el asesinato de Marat, Charlotte Corday declaró que actuó por cuenta propia, con el fin de evitar un mayor derramamiento de sangre, señalando que "maté a un hombre para salvar a cien mil". Cuatro días más tarde sería ajusticiada bajo el filo de la guillotina. El asesinato de Marat engrandeció su imagen en los sectores marginales de la sociedad, transformándose a partir de entonces en un mártir de la Revolución, iniciándose el culto a su persona ${ }^{1-3}$.

¿Héroe y mártir o un mero extremista sanguinario? Con la imparcialidad y serenidad que pueden aportar dos siglos transcurridos desde la Revolución Francesa, reservo al lector el juicio valórico que pueda realizar a la persona de Jean-Paul Marat, a la luz de las diversas fuentes históricas disponibles. Resulta interesante constatar un común denominador en las principales facetas de su vida -médico, científico y revolucionario- cual es el nunca haber sido indiferente para quienes le conocieron, generando sentimientos extremos: admiración e idolatría en unos, desprecio y odio en otros, sentimientos que persisten en la opinión de muchos estudiosos de la historia hasta el día de hoy.

\section{Referencias}

1. Rossi A. Los médicos y la Revolución Francesa. Marat, médico y político revolucionario. Rev Asoc Méd Argent 2007; 120: 13-19.

2. Llobet J. Jean-Paul Marat y la Ilustración Penal. Revista CENIPEC 2006; 1: 273-306.

3. Jean-Paul Marat. En: Encyclopaedia Britannica. Disponible en: http://www.britannica.com/EBchecked/topic/363841/Jean-Paul-Marat [Consultado el 30/09/08]. 2008.

4. Tosi L. Jean-Paul Marat (1743-1793). Cientista e tradutor de Newton. Quím Nova 1999; 22: 907-12.

5. Jelinek JE. Jean-Paul Marat: the differential diagnosis of his skin disease. Am J Dermatopathol 1979; 1: 251-2.

6. Lipman JH, Lipman E. Doctor Marat and his skin. Med Hist 1958; 2: 281-6.

7. Nicolas M, Krause P, Gibson L, Murray J. Dermatitis herpetiformis. Int J Dermatol 2003; 42: 588-600.

8. Oxentenko A, Murray J. Celiac disease and dermatitis herpetiformis: the spectrum of gluten-sensitive enteropathy. Int J Dermatol 2003; 42: 585-7.

9. Fry L. Dermatitis herpetiformis: problems, progress and prospects. Eur J Dermatol 2002; 12: 523-31.

10. Shuster $\mathrm{S}$. The nature and consequence of Karl Marx's skin disease. Br J Dermatol 2008; 158: 1-3.

11. Jemec GBE. The revolutionary consequences of skin disease. Br J Dermatol 2008; 158: 1371-401. 